\title{
Analysis of Business Intelligence Applications in Healthcare Organizations
}

\author{
Mona Isazad Mashinchi \\ Insight Centre for Data \\ Analytics, Prostate Cancer \\ Institute, NUI Galway \\ Mona.Isazad@insight- \\ centre.org
}

\author{
Adegboyega Ojo \\ Insight Centre for Data \\ Analytics, NUI Galway \\ adegboyega.ojo@insight- \\ centre.org
}

\author{
Francis J. Sullivan \\ Prostate Cancer Institute, NUI \\ Galway \& Galway Clinic \\ Frank.sullivan@galwayclinic.co \\ $\mathrm{m}$
}

\begin{abstract}
In today's healthcare (HC) market there are lots of pressures on HC organizations (Os). Besides, many challenges including; demographic changes and the need to manage vastly increasing data volumes in HC, have motivated these organizations to adopt business intelligence (BI) solutions. Through a systematic review of the literature, this study establishes the patterns of BI adoption in the HC domain by examining the nature of BI solutions in use, expected outcomes from BI use, specific types of BI capabilities deployed, and aspects of HCOs directly impacted. Findings from our study provide a foundation for future research agenda on BI in Healthcare. We conclude by highlighting the shortcomings of current BI practice in the HC domain in the context of the emerging value-based (VB) $\mathrm{HC}$ delivery model and the need for research in this direction.
\end{abstract}

\section{Introduction}

Growing global demand and changes in the $\mathrm{HC}$ industry are rising tremendously these days [1][2]. At the same time, $\mathrm{HC}$ industries all over the world are struggling with many challenges including the burden of increasingly complicated chronic disease and rising costs [3].

Internal and external actors in this industry need data and analytic skills to achieve the best outcomes [4]. Internal actors in $\mathrm{HC}$ industry such as doctors, and managers must be able to easily access and utilize "up-to-date information, at the right time and in the right place, every time" to provide better health services and make the best decision cost-effectively. External actors, for instance, patients, should be able to access their health records in order to be able to self-manage their health status and have an active role (instead of passive role) in their treatment decisions and overall health. Hospitals need systems that not only help them to manage data but also facilitate extracting information from data. This is where BI systems as a strategic solution come into the picture. BI systems lead to improved patients' outcomes and safety, increased revenue, reduced costs and increased efficiency [3][4][5][6][7]. The implementation of $\mathrm{BI}$ systems becomes an undeniable imperative in the $\mathrm{HC}$ industry because it can provide precise information for best decisions [4]. BI potential benefits have placed it as a top priority of the health policy agenda in the world [8].

$\mathrm{BI}$ is a collection of decision support technologies which provides information and knowledge from a variety of sources, analyze them and present them in a user-friendly fashion, to facilitate decision-making processes [9][10]. Governments are investing billions of dollars to encourage actors in the HC industry to adopt health Information Technology (IT) to improve patients' outcomes [11]

One of the limitations of publications about BI adoption in $\mathrm{HC}$ is the uncertainty regarding its effects on patients' outcomes. So in this study, we evaluate $\mathrm{BI}$ applications in $\mathrm{HC}$, and we wish to assess the degree to which the use of BI systems can improve the health outcomes for patients. To our knowledge, this is one of the earliest studies which analyze BI capabilities impacts on patients' health outcomes improvement by applying the VBHC approach. The results of this study take the $\mathrm{HC}$ managements sector one step closer to a deeper insight into the circumstance and required changes in this industry.

The remainder of the paper is organized as follows; the next section introduces the theoretical background, section 3 expands on the research methodology. Section 4 analysis BI application in the $\mathrm{HC}$ industry and section 5 examine results and findings. The discussion is presented in section 6 , and finally, section 7 presents the conclusion and future works.

\section{Background}


Actors in the $\mathrm{HC}$ domain are faced with many challenges; such as analyzing enormous amounts of information at many different levels in hospitals in attempting to deal with complex HC problems [4], increasing in population, patient poor role in treatment decision, lack of cooperation in current $\mathrm{HC}$ system, long waiting time for receiving treatment and many dissatisfied patients [12].

In HCOs different types of data need to be extracted, cleaned, integrated, analyzed and established to different internal/external actors for better decision making and data management.

Given the challenges, complexity, sensitive nature associated with $\mathrm{HC}$ domain, one might conclude that HCOs could benefit from systems and technologies, including the adoption of BI, that aid in handling and analyzing a vast amount of data [10]. Physicians might use such technologies to analyze patient data and to predict outcomes of different treatments [13].

With these requirements in $\mathrm{HC}, \mathrm{BI}$ systems' four major capabilities: organizational memory capabilities, information integration capabilities, insight creation capabilities and presentation capabilities make BI imperative for the $\mathrm{HC}$ domain [5][9]. The goal of BI is to provide high-quality information, at the right time to the right person, in the right location, every time [14]. Different organizations regarding their needs, goals, and requirements apply these capabilities.

$\mathrm{BI}$ in the $\mathrm{HC}$ field potentially improves service quality, competitiveness, patient safety and satisfaction. It gives doctors the ability to identify uncovered patterns in data, recognize patients at risk, reduce costs and errors, enhance supply chain performance, manage risks and accelerate performing tasks. Actors in $\mathrm{HC}$ field can easily and quickly create reports such as dashboards with BI tools developed by BI vendors, such as; Tableau, Qlik and Microsoft Power BI to better present data and information [15]. All these advantages can improve care processes and importantly, patient's outcome. BI application can bring value for patients and all other actors in $\mathrm{HC}$ area by providing access to accurate data, information and analytic tools [3][4][10][16][17]. Additionally, profitability and quality analysis gained through BI can contribute toward a deep insight into organizational objectives. Besides, Resources in HCOs could be used more efficiently, by applying BI solutions and techniques [3][17].

\section{Methodology}

\subsection{Research objectives and questions}

This study aims to analyze literature on BI applications in the $\mathrm{HC}$ domain, especially in hospitals. In particular, it seeks to examine the specific nature of BI solutions in use and results obtained as the basis for establishing the overall research trends in the domain. Findings will indicate areas where future research efforts could be targeted. Specific objectives of the study include:

1. Determining goals in HCOs which motivate providers in this domain to apply BI as a strategic tool.

2. Understanding the nature of the BI solutions employed in $\mathrm{HC}$ domain.

3. Assessing the effects of using BI, by identifying the results of utilizing it and importantly to interpret their association with various end-users and beneficiaries, specifically patients and health professionals/hospitals.

4. Eliciting the research gaps by identifying research issues and informing $\mathrm{HC}$ Informatics the potential areas for further research.

Guided by these objectives, the study answers the following questions:

I. What are the goals of planners in HCOs in adopting BI solutions?

II. What types of BI capabilities and solution were employed?

III. What are the impacts of BI utilization on HCOs?

IV. What are the areas of "BI application in $\mathrm{HC}$ " which are less studied and warrant more research?

\subsection{Research method}

The research method in this study is the content/literature analysis. The primary source of data was Journal articles and conference paper related to $\mathrm{BI}$ application in $\mathrm{HC}$ domain. Inclusion and exclusion criteria were based on the papers topics, keywords, and abstracts. By considering the research background (section 2), we are going to map studies which applied BI in their HC organizations, in five dimensions, including a) types of BI capabilities, b) research goal, c) research outcomes, d) applied tools, techniques, and solutions, and E) research gap. The aim is to analyze papers based on these dimensions.

Definitions for these dimensions are highlighted below:

1) Research goal - clarifying challenges and goals which motivated the planner in hospitals to consider 
BI as a solution for their problems, or as a compelling factor to reach their targets.

2) Types of BI capabilities - It refers to the types of BI capability which organizations are mostly adopting. In this study, capabilities are defined as 1Organizational Memory Capabilities, 2- Information Integration Capabilities, 3- Insight Creation Capabilities, and 4- Presentation Capabilities.

3) Applied tools, techniques, and solutionsDescribing the nature of the BI solutions and technologies applied.

4) Research outcomes - It refers to the effect of using BI in HCOs.

5) Research gap - It refers to gaps in studies analyzed.

In this research, the following four databases were used: ACM Transactions, Google Scholar, IEEE Explore, and ScienceDirect. The following keywords were used to search relevant documents: "healthcare," "health care," "business intelligence," "business intelligence and healthcare/ health care and value-based healthcare" - in titles, abstract and keywords lists.

At this stage, after removing duplication papers and excluding those papers which did not discuss BI in the healthcare domain, we retrieved 288 documents. Following a review of the abstracts, 173 papers were selected for full-text analyze. In the end, after analyzing all full-text and identifying 17 additional references (from citation search), 50 documents were used, which 24 of them were case studies, 13 of them were about value-based healthcare, two of them were books and others were about BI and its capabilities and advantages.

The focus was on English papers which mostly published between 2010-2017, we choose this period, since this paper's aim is analyzing BI impacts on health outcomes by focusing on health outcomes value improvements in $\mathrm{HC}$, and the first paper in value-based HC model was published in 2010, so we were more interested in analyzing the intersection between these two topics after 2010. Moreover, results from the search in Scopus shows most of the studies about BI applications in the $\mathrm{HC}$ domain are published after 2010 .

\section{Analysis}

This section presents an analysis of the research publications based on the methodology described in section three as the support for answering the research questions. Section 4-1 examine the goals of studies applying BI in HCOs; section 4-2 attempts to determine what types of BI capabilities, solutions, and tools were adopted in HCOs. Section 4-3 focuses on BI solutions outcomes, while research gaps in the domain (BI in HC) are highlighted in section 4-4.

\subsection{Healthcare organizations goals of applying business intelligence}

This section analyzes the goal of healthcare organization of applying BI as a robust solution. We identified hospitals/ HCOs are using BI systems for four main reasons, and we categorize them as follows: "hospital process performance improvements," "clinical care and disease improvements," "analyzing hospitals process performance" and "managing data and better communication and collaboration" (Figure 1) (Table 1).

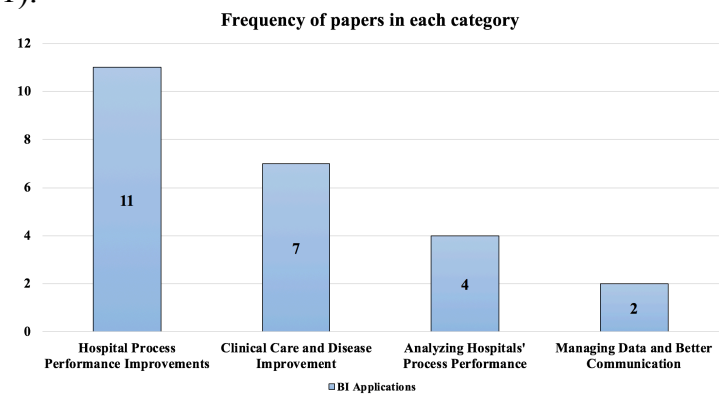

Figure 1. Four dimensions of $\mathrm{BI}$ applications in healthcare

Table 1. Dimensions of BI applications goals in healthcare organizations

\begin{tabular}{|c|c|c|}
\hline Goals & Descriptions & Sources \\
\hline $\begin{array}{c}\text { Hospital } \\
\text { process } \\
\text { performance } \\
\text { improvements }\end{array}$ & $\begin{array}{l}\text { Improving } \\
\text { Infection rate, } \\
\text { improving } \\
\text { surgical } \\
\text { process } \\
\text { issues; Better } \\
\text { leveraging } \\
\text { data, improve } \\
\text { in revenue } \\
\text { and workflow, } \\
\text { Improving cost } \\
\text { and time }\end{array}$ & $\begin{array}{c}\text { Osama et al [7]; } \\
\text { Danilo et al [4]; } \\
\text { Celina and } \\
\text { Kornelia [3]; } \\
\text { Kern [18]; Calkin } \\
\text { [19]; } \\
\text { Ragush and } \\
\text { Wholgemuth } \\
\text { [20]; Randheer } \\
\text { et al [21]; } \\
\text { Ferranti et al } \\
\text { [22]; Machad } \\
\text { [23]; } \\
\text { Almeida [24]; } \\
\text { Mustafee [25] }\end{array}$ \\
\hline $\begin{array}{l}\text { Clinical care } \\
\text { and disease } \\
\text { improvements }\end{array}$ & $\begin{array}{c}\text { Identify } \\
\text { patients at } \\
\text { risk, Improving } \\
\text { and optimizing } \\
\text { the treatment, }\end{array}$ & $\begin{array}{l}\text { DeGaspari [26]; } \\
\text { Vedamanikam et } \\
\text { al [27]; QlikTech }\end{array}$ \\
\hline
\end{tabular}




\begin{tabular}{ccc} 
& explore & International \\
& pattern in & [28]; Osama et \\
patient data & al [29]; Kelvin et \\
& and & al [30]; Loreto et \\
& preventing & al [31]; \\
& acute & Wickramasinghe \\
& condition & et al [32] \\
Analyzing & Developing & Simms et al [33]; \\
hospitals' & clinical & Gonçalves et al \\
process & indicator for & [14]; Cristiana et \\
performance in & services & al [34]; Ivan et al \\
specific & quality & [13] \\
department & measurement, & \\
& patient quality & \\
of life analysis & \\
Managing data & Better data & Carte et al [35]; \\
and better & management & Ahmad et al [36] \\
communication & and creating a & \\
and & unique & \\
collaboration & repository & \\
\hline
\end{tabular}

\subsubsection{Hospital process performance} improvements. We found that about $45 \%$ (of 24) of studies focus were on hospital process performance improvements (Table 1). In the related studies, researchers used BI to improve specific issues in their processes, either in one department or in the whole hospital. For instance according to Osama and et al. [7], at the London Health Sciences Centre, BI technology and solution were applied to improve the infection rate. They changed hospital's old systems from online transactional processing (OLTP) to online analytical processing (OLAP) BI solution. In another study at Torbay Hospital, responding to the challenge of overcrowding with the rate of Emergency Department attendance, a web-based BI application was designed to provide patients with real-time access to information about waiting time [25]. In Portugal, Danilo et al. used BI in a Portuguese hospital to improve the surgical process issues [4]

4.1.2. Clinical care and disease improvements. In the second group of studies (29\% of 24 cases) researchers used BI with the aim of clinical care and disease improvements (Table 1). Our analysis showed that applying computer technology to track, monitor and analyze the medical and clinical data is one of the essential aspects of disease management. $\mathrm{BI}$ as a collection of decision support technologies, techniques and capabilities can enable clinicians to explore patterns in data, identify patients at risk [26][5][27][30], improve treatment procedure [28][5][29], prevent acute conditions [27] and develop clinical indicator to measure the quality of services [31][32]. We gathered from related studies that managers in HCOs developed BI solutions to empower clinicians/staff in decision making (operational, tactical and strategic decisions) and to improve the care process. As an example, in Ontario, BI was applied to improve the care of patients with hip fraction [29]. In another study due to the high rate of lung cancer in the world, researchers in the USA applied different DM techniques: Decision Tree, Naïve Bayes, and Clustering to predict lung cancer occurrence, based on some risk factors [27]

4.1.3. Analyzing hospital process performance. The third group of studies applied BI technologies and solutions to analyze a specific process in their organization and to measure the quality of service (Table 1). These measurements helped actors in related HCOs to identify problematic areas and to decide whether improvement should be taken. As an example, Rebecca et al. [33] to identify ongoing issues in maternity units developed a maternity dashboard across the UK.

4.1.4. Managing data and better communication and collaboration. The last group of studies used BI solutions to manage different types of data in their organizations and to improve internal communications and collaborations among staffs and in somehow to improve patients' access to health professionals (Table 1). BI application in the Cardinal Health organization is an example of studies in this category. Here, BI solutions and tools including SAP R/3 and solid data warehouse were used to achieve better data accessibility, communication, and collaboration among departments. This implementation led to a reduction in IT infrastructure cost and better data management [35].

\subsection{Business intelligence capabilities and solutions in healthcare organizations}

This section provides detail about BI capabilities, solutions and techniques applied in HCOs. As highlighted in section two, BI has four primary capabilities (organizational memory capabilities, information integration capabilities, insight creation capabilities and presentation capabilities) which organizations based on their aim, choose them. These capabilities are different but dependent on each other [9]. In the table below (Table 2) detail of capabilities and tools which are used by HCOs can be seen. 
Table 2. Applied BI capabilities and tools

\begin{tabular}{|c|c|c|}
\hline BI Capabilities & $\begin{array}{l}\text { BI Tools and } \\
\text { Techniques }\end{array}$ & Sources \\
\hline $\begin{array}{c}\text { Organizational } \\
\text { Memory } \\
\text { Capabilities }\end{array}$ & $\begin{array}{l}\text { SAP R/3; } \\
\text { Solid data } \\
\text { warehouse }\end{array}$ & $\begin{array}{l}\text { Carte et al [35]; } \\
\text { Ahmad et al [36] }\end{array}$ \\
\hline $\begin{array}{l}\text { Information } \\
\text { Integration } \\
\text { Capabilities }\end{array}$ & $\begin{array}{c}\text { EMR; } \\
\text { integrated } \\
\text { data } \\
\text { warehouse; } \\
\text { Diver } \\
\text { Platform; } \\
\text { Web based } \\
\text { BI } \\
\text { application }\end{array}$ & $\begin{array}{l}\text { DeGaspari [26]; } \\
\text { Kern [18]; } \\
\text { Mustafee [25] }\end{array}$ \\
\hline $\begin{array}{c}\text { Insight } \\
\text { Creation } \\
\text { Capabilities }\end{array}$ & $\begin{array}{c}\text { Solid } \\
\text { database; } \\
\text { data mining } \\
\text { (DM) } \\
\text { techniques; } \\
\text { QlikView }\end{array}$ & $\begin{array}{l}\text { Vedamanikam et } \\
\text { al [27]; QlikTech } \\
\text { International [28] }\end{array}$ \\
\hline $\begin{array}{l}\text { Presentation } \\
\text { Capabilities }\end{array}$ & $\begin{array}{c}\text { OLAP; DM; } \\
\text { Dashboard; } \\
\text { Scorecard; } \\
\text { Simple.BI; } \\
\text { Comarch BI; } \\
\text { IBM Watson } \\
\text { Analytics } \\
\text { platform; } \\
\text { power BI; } \\
\text { SAP HANA; } \\
\text { SAP Lumira; } \\
\text { SAP } \\
\text { Predictive } \\
\text { Analytics; } \\
\text { Pentaho } \\
\text { Business } \\
\text { Analytics } \\
\text { Platform; } \\
\text { HVITAL } \\
\text { analytic } \\
\text { platform }\end{array}$ & $\begin{array}{c}\text { Osama et al [7]; } \\
\text { Osama et al [29]; } \\
\text { Danilo et al [4]; } \\
\text { Celina and } \\
\text { Kornelia [3]; Calkin } \\
\text { [19]; Ragush and } \\
\text { Wholgemuth [20]; } \\
\text { Randheer et al } \\
\text { [21]; Simms et al } \\
\text { [33]; Kelvin et al } \\
\text { [30]; Gonçalves et } \\
\text { al [14]; Cristiana et } \\
\text { al [34]; Loreto et al } \\
\text { [31]; } \\
\text { Wickramasinghe } \\
\text { et al [32]; Ivan et } \\
\text { al [13]; Ferranti et } \\
\text { al [22]; Almeida } \\
\text { [24]; Machad [23] }\end{array}$ \\
\hline
\end{tabular}

4.2.1. Organizational memory capabilities. Organizational memory capability delivers historical knowledge and information, and thus provide valuable input for information integration. It is BI foundational capability which stores data, information, and knowledge from different sources in a unique database which then can be easily accessed and used by different users [9]. Our analysis shows those cases which aimed to manage data better and improve their collaboration mostly focused on this capability to manage their historical data properly [36][35].

\subsubsection{Information integration capabilities.} Information integration, in turn, linked all relevant types of data inside and outside the organization. This capability could provide the required input for Insight creation capability [9][26]. For instance, the NorthShore University Health System employed an integrated data warehouse to enable clinical care improvement, an easier discovery of patterns inside data, identifying patients at risk and reducing heart attack rate among patients [26]. Outputs of information integration capabilities can be used as input for insight creation capabilities.

4.2.3. Insight creation capabilities. Insight creation by applying analytics techniques to data and information gives new insight into them and helps organizations to make better and more informed decisions. It affords different types of analysis (descriptive, diagnostic, predictive, and prescriptive) and facilitates better, faster and more accurate decisions for users. The outcome of insight creation capability facilitates presentation capability. For instance, according to Vedamanikam et al. [27], a database and data mining tools were used to improve the clinical care of the patient with cancer and to recognize patient at risk and prevent acute conditions. Specifically, the entity involved applied data mining techniques including Decision Tree, Naïve Bayes, and Clustering techniques on data for analysis, finding patterns in data and predicting risk level of patients.

4.2.4. Presentation capabilities. Presentation capability displays generated insights and information in a user-friendly form. It helps different users in decision making to expose the most insightful information at a glance [9][5]. For example, in Duke University Health System, realtime access to data, easily asking dynamic questions, identifying issues in processes, financial effectiveness, and patient safety improvement was supported using an Integrated data warehouse and designed dashboards. Visualizations helped users (by various goals) to better understand information in a user-friendly platform and make more effective decisions [22].

\subsection{Business intelligence outcomes in $\mathrm{HC}$ domain}

This section covers types of BI impacts and outcomes on HCOs found in the extant literature. While in some cases, researchers did not define BI 
impacts on HCOs [14][19][20][30][33], others elaborate on BI solutions outcomes. Applying BI in the $\mathrm{HC}$ domain has so many consequences and impacts and changes the way that HCOs do their business. In this study, we identified and coded BI impacts as follows: "data management," " cost," "decision making," "collaborations," "efficiency," "quality and quantity of HC services," "workflow process," "satisfaction," "outcome. " We describe the sources of these outcomes in Table 3 below.

Table 3. BI outcomes in healthcare organizations

\begin{tabular}{|c|c|c|c|c|c|c|c|c|c|}
\hline Source & \multicolumn{9}{|c|}{ BI Impacts on Healthcare } \\
\hline $\begin{array}{l}\stackrel{0}{E} \\
\frac{\pi}{2} \\
\frac{0}{2} \\
\frac{0}{0} \\
\frac{D}{1} \\
\frac{1}{4}\end{array}$ & 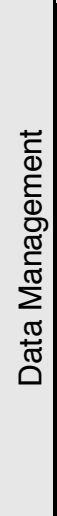 & 范 & 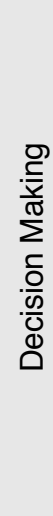 & 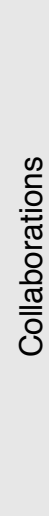 & 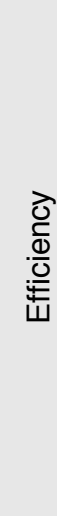 & 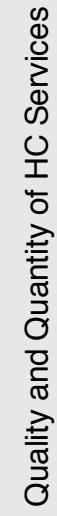 & 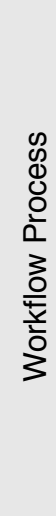 & 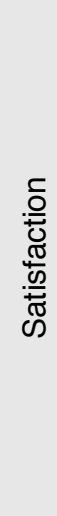 & 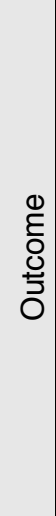 \\
\hline $\begin{array}{c}\text { DeGas } \\
\text { pari } \\
{[26]}\end{array}$ & $\checkmark$ & & $\checkmark$ & & & & $\checkmark$ & & \\
\hline $\begin{array}{c}\text { Vedam } \\
\text { anikam } \\
\text { et al } \\
{[27]}\end{array}$ & $\checkmark$ & & $\checkmark$ & & & & $\checkmark$ & & \\
\hline $\begin{array}{l}\text { Osama } \\
\text { et al [7] }\end{array}$ & $\checkmark$ & $\checkmark$ & $\checkmark$ & & $\checkmark$ & $\checkmark$ & & & \\
\hline $\begin{array}{c}\text { QlikTec } \\
\text { h [28] }\end{array}$ & $\checkmark$ & $\checkmark$ & $\checkmark$ & & $\checkmark$ & $\checkmark$ & $\checkmark$ & & $\checkmark$ \\
\hline $\begin{array}{l}\text { Macha } \\
\text { d [23] }\end{array}$ & $\checkmark$ & & $\checkmark$ & & & & & & \\
\hline $\begin{array}{l}\text { Carte } \\
\text { et al } \\
{[35]}\end{array}$ & $\checkmark$ & $\checkmark$ & $\checkmark$ & $\checkmark$ & & & & & \\
\hline $\begin{array}{c}\text { Osama } \\
\text { et al } \\
\text { [29] }\end{array}$ & $\checkmark$ & & $\checkmark$ & & $\checkmark$ & $\checkmark$ & $\checkmark$ & & \\
\hline $\begin{array}{l}\text { Danilo } \\
\text { et al [4] }\end{array}$ & $\checkmark$ & $\checkmark$ & $\checkmark$ & & $\checkmark$ & $\checkmark$ & $\checkmark$ & & \\
\hline
\end{tabular}

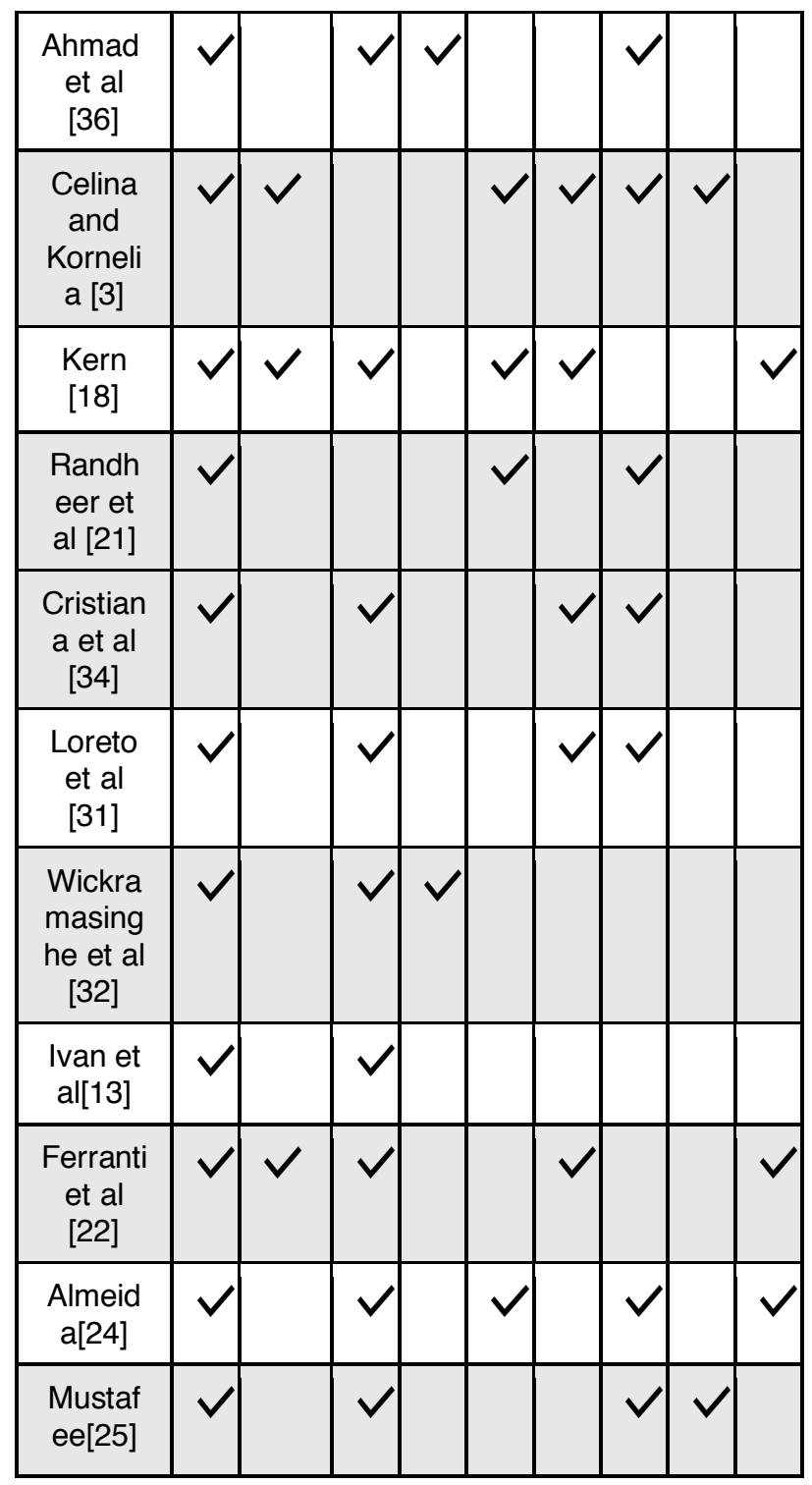

\subsection{Research gap}

By analyzing publications about BI application in $\mathrm{HC}$ domain, identifying challenges, potential opportunities for $\mathrm{BI}$ in $\mathrm{HC}$, evaluating the HCOs aims and intentions of using $\mathrm{BI}$ tools, techniques and examining the outcomes of BI, we identified some research gaps in this field. These research gaps are areas that could be considered by researchers and scholars for more investigations.

On the one hand, Although BI and its analytical capability are very critical in today's world and bring so much benefit to organizations, our analysis could not find many publications regarding BI success factor and comprehensive frameworks for implementing $\mathrm{BI}$ in $\mathrm{HC}$ domain successfully. 
Considering the BI capabilities, we could not find studies which investigate the importance of BI capabilities regarding their benefits and outcomes. Publications on the financial justification of BI different capabilities in the $\mathrm{HC}$ domain are rarely studied which need to be considered by researchers.

On the other hand, in the area of BI outcome in HCOs, the collaboration, satisfaction, and patients health outcome are understudied with relative to the rest. BI applications studies in healthcare organizations are mostly focused on hospital process performance improvements and clinical care and disease improvements rather than analyzing processes performance and improving communication and collaboration in the organizations. Furthermore, the number of studies which aim to improve patients health outcome are limited. In fact, BI roles and effects on patients health status are rarely studied and mostly researchers investigate BI impacts from the organizational perspective.

Moreover, additional high-quality research studies need to be conducted to obtain evidence of BI efficacy in $\mathrm{HC}$ domain and establish guidelines for its successful implementation.

\section{Results and findings}

This section summarises the findings of the study concerning the research questions.

I- Goals of applying BI Analyzing on studies shows that HCOs may use BI for four primary reasons to cope with the challenges and problems (challenges introduced in section two) that they have. These four fundamental reasons can be defined as "hospital process performance improvements," "clinical care and disease improvements," "analyzing hospitals process performance" and "managing data and better communication and collaboration."

II- BI capabilities and solution Based on the literature, we found $\mathrm{BI}$ has four fundamental capabilities which help organizations to achieve their targets (section 4.2). Few HCOs which their focus were on organizational memory capabilities were looking for a solid database that helps them to store their historical data in order to manage them better. Some other studies which aimed to have a unique data warehouse that enables them to have easier and faster access to all types of data from different time points focused on information integration capabilities of BI. The third group of study applied BI insight creation capabilities to analyze the stored data in their organizations and to uncover the pattern in data. Finally, the last group of research (which formed the majority of publication) applied presentation capabilities of BI. They were trying to visualize created information and knowledge in a user- friendly fashion such as the dashboard, scorecard, etc., to make them easier to understand. From an analysis point of view, DM techniques and OLAP were vastly used by HCOs to analyze the data and to discover the patterns. Furthermore, In some cases, BI vendors (such as Qlik, Simple.BI, Comarch BI, IBM and power BI) solutions were applied in HCOs to achieve the goal of adopting BI.

III- Impacts of BI utilization To clarify the influences of BI, and based on our knowledge from analyses, we distinguished between BI solutions impacts on HCOs and patients. On the one hand, from an organizational point of view, we categorized them in 6 domains; "data management," "cost," "decision making," "collaborations," "efficiency" and "quality and quantity of HC services." Generally, applying BI in HCOs in many cases improved data management and decision-making process. HCOs could have access to data easier, faster and more accurately. It helps them to improve their quality of process and services and reduces the cost of duplicated works and errors, and helped them to use resources more efficiently. We found that in a few cases it helps providers to have better collaboration and communication with each other.

On the other hand, we categorized BI impacts on patients into three areas, "workflow," "satisfaction" and "outcome." Studies show in many cases the BI application improved patient workflow in hospitals, such as waiting time and faster treatment procedure. In addition, somehow in a few cases, it improved patients' satisfaction and outcome (not mentioned what types of outcomes).

IV- Less studied areas - Considering studies analyze, and importance of this field, some research gaps can be defined as follow. Although many studied apply BI successfully in their organization, there are some cases which fail in applying BI. So there is a need for more research regarding BI success factors and framework in the $\mathrm{HC}$ domain. Studies do not reflect how BI and its capabilities impact on decisions. Furthermore, researchers have neglected studies about assessing BI impacts and roles on patient outcome improvements. Mostly the focus of studies is on organizational process improvement.

\section{Discussion}

Despite widespread use of BI technologies and solution in the $\mathrm{HC}$ domain to improve health outcome for patients, there is no convincing evidence 
from our analysis which supports this assumption. It appears that HCOs typically use BI to control the quality of health services and to improve data management, internal processes, and efficiency, rather than improving health outcomes for patients.

There is a significant gap between process improvements through BI application and patients health outcome improvements. However, process measurements and improvement are good; they are not enough. HCOs need to measure outcomes/results around patient medical condition and try to improve them [12]. Although better data management, providing lots of services (by improving patients workflow) and excellent experience in a timely base for patients by the help of decision supports systems are necessary, they do not assure good health outcome for patients [37].

We believe, studies which investigate BI effects on patient health outcomes are mostly overlooked by researchers in this domain. In today's $\mathrm{HC}$ industries there are so many quality and process measurements and improvements rather than patients health outcome improvement.

We found most of the problems in the $\mathrm{HC}$ system are because of the current approaches to managing HCOs which are not viable to cope with contemporary challenges. Hence, management systems in HCOs do not apply BI as a way to promote patient health outcomes, due to the lack of data to analyze [38].

By further analysis on publications, we discovered it is essential for HCOs to change their health delivery model and focus to the goal of "value" improvements for patients (all efforts in HCOs such as applying BI or other IT infrastructures need to be around patients value improvement), where the value is defined as patient's health outcomes improvements achieved, relative to the cost of delivering the required treatment [1][39][37][40][41][42][12][43][44]. This new health delivery model which initially introduced by Porter and Teisberg called value-based healthcare (VBHC) and could be considered as a roadmap for HCOs [45]. This strategy in the $\mathrm{HC}$ domain has been created to confront many highlighted challenges and gap in this study. This system aims to align patients, providers, and funders toward the shared goal of improving quality and outcome with lower costs [46].

If value improves, it is expected to benefit not only patients regarding their short and long-term health outcomes but also health planners, providers, employers and governments can realize essential gains, while the economic sustainability of the $\mathrm{HC}$ system improves [37][1].
Evaluation of patients' health outcome, experience and cost are critical as they are the factors which matter to patients. Collecting correct information, data and analyzing them is one of the keys for improving the value for patients, which all can be facilitated by BI capabilities [47][48][49][50]. HC industry for value measurement needs to have access to precise, actionable, reliable, completeness and comprehensiveness data on the two elements driving the value (health outcome and cost). The results of this value measurement and other data about patient health status and cost will need to be shared in a transparent way with actors (patients, other HCOs, etc.) in this domain.

It has been demonstrated, that accessing and analyzing high-quality data, designing modern interactive style of reports such as interactive dashboards, and finally sharing them with others, are very important for an organization's success in $\mathrm{HC}$ domain [13][44].

Therefore, regarding all these requirements, BI as an enabler can provide high-quality information, at the right time to the right person, in the right location [44]. Accordingly, BI, data analytics tools and techniques and other IT infrastructure could synergistically be combined with existing organizational resources (tangible, intangible), functions and processes to not only improve outcome, cost and value, but also to provide all necessary data and information, and to facilitate calculations for value measurements.

Broadly speaking, these movements from traditional hospital management system to VBHC model with the help of BI capabilities supposed to be a win/win strategy for all people involved in the $\mathrm{HC}$ systems. Firstly, patients will have the right to choose the best person/hospital with best value/skills/outcome among others. Therefore, the patient would not have to pay more money for duplicated tests in different departments and resources would be used more efficiently and at the end, they would be healthier. Secondly, VBHC delivery model will increase the competition among doctors and hospitals. They all will try to improve the outcome for patients to attract more patients. Also, reports about values and outcome can probably be very useful/ interesting for other external actors in the $\mathrm{HC}$ domain, such as insurance company. It can motivate them to work with those hospitals which create better outcome and value with more efficient use of resources.

\section{Conclusions}


We have attempted a critical analysis of $\mathrm{BI}$ in $\mathrm{HC}$ research landscape in this paper. Our findings have revealed the major BI goals in HCOs as well as the types of impacts that have resulted from BI use in these organizations. We discovered that the extant literature in this domain has primarily focused on improving processes, data management, cost and services of the organization, and not on patients outcomes improvements. This pattern we have argued does not align well with the changing HC delivery model to VBHC. In this emerging model, decision support systems are seen as an enabler for patient outcome improvement and strategy for overall health outcome improvement in which minimizes or eliminates unnecessary cost.

In our opinion, for HCOs to operate competitively with significantly improved patient outcomes BI practices in $\mathrm{HC}$ must be re-thought. We, therefore, consider research that will re-frame BI applications in this emerging context and seek to understand the conditions for effective use of $\mathrm{BI}$ in $\mathrm{VBHC}$ as critical for progress in the domain.

\section{Acknowledgments}

This study is supported by the Irish Research Council (IRC) and Galway Clinic Hospital.

\section{References}

[1] S. Gentry and P. Badrinath, "Defining Health in the Era of Value-based Care: Lessons from England of Relevance to Other Health Systems," Cureus, 2017.

[2] T. Mettler and V. Vimarlund, "Understanding business intelligence in the context of healthcare," in Health Informatics Journal, 2009.

[3] C. Olszak and K. Batko, "The Use of Business Intelligence Systems in Healthcare Organizations in Poland," 2012.

[4] D. Coelho, J. Miranda, F. Portela, J. Machado, M. F. Santos, and A. Abelha, "Towards of a Business Intelligence Platform to Portuguese Misericórdias," in Procedia Computer Science, 2016.

[5] N. Ashrafi, L. Kelleher, and J.-P. Kuilboer, "The Impact of Business Intelligence on Healthcare Delivery in the USA," Interdiscip. J. Inf., vol. 9, no. 9, pp. 117-130, 2014.

[6] P. Brooks, O. El-Gayar, and S. Sarnikar, "Towards a business intelligence maturity model for healthcare," in Proceedings of the Annual Hawaii International Conference on System Sciences, 2013.

[7] O. T. Ali, A. B. Nassif, and L. F. Capretz, "Business intelligence solutions in healthcare a case study: Transforming OLTP system to BI solution," 2013 3rd Int. Conf. Commun. Inf. Technol. ICCIT 2013, pp. 209-214, 2013.

[8] J. S. Mccullough, S. Parente, and R. Town, "Health Information Technology and Patient Outcomes: The Role of Organizational and Informational Complementarities," NBER Work. Pap. No. 18684, 2013.

[9] R. Sabherwal and I. Becerra-Fernandez, BUSINESS INTELLIGENCE : PRACTICES, TECHNOLOGIES, AND MANAGEMENT. Hoboken, NJ : Wiley, 2011.

[10] B. G. Geetha, I. M. Umesh, and R. B. R. Varma, "A STUDY ON APPLICATIONS OF DATA ANALYTICS IN NON-BUSINESS DOMAINS," vol. 6, no. 8, pp. 1249-1251, 2017.

[11] S. K. Brenner et al., "Effects of health information technology on patient outcomes: A systematic review," J. Am. Med. Informatics Assoc., vol. 23, no. 5, pp. 1016-1036, 2016.

[12] M. E. Porter and E. Olmsted Teisberg, Redefining Health Care: Creating Value-Based Competition on Results. Harvard Business School Press, 2006.

[13] M.-L. Ivan and M. Răducu TRIFU, "Using Business Intelligence Tools for Predictive Analytics in Healthcare System," IJACSA) Int. J. Adv. Comput. Sci. Appl., vol. 7, no. 5, 2016.

[14] D. Gonçalves, M. Y. Santos, and J. Cruz, "Analysis of the Quality of Life After an Endoscopic Thoracic Sympathectomy: A Business Intelligence Approach," 2010.

[15] J. Schlegel, Kurt; Sallam, Rita L.; Yuen, Daniel; Tapadinhas, "Magic Quadrant for Business Intelligence and Analytics Platforms," 2017.

[16] A. Gaddum, "Business Intelligence (BI) for Healthcare Organizations," 2012.

[17] E. T. Chen, "Communications of the IIMA Implementation Issues of Enterprise data Warehousing and Business Intelligence in the Healthcare Industry Implementation Issues of Enterprise Data Warehousing and Business Intelligence in the Healthcare Industry," vol. 12, no. 2, 2012 .

[18] C. Kern, "Western Maryland Health System Successfully Shifts To Value-Based Care Model," 2016. [Online]. Available:

https://www.healthitoutcomes.com/doc/westernmaryland-health-system-successfully-shifts-tovalue-based-care-model-0001.

[19] S. Calkin, "Nurse ratios to be published by trusts for first time," Nurs. Times, 2012.

[20] S. Ragush and N. Wohlgemuth, "How is Saskatchewan's health care system performing?," Longwoods, 2011. [Online]. Available: http://www.longwoods.com/newsdetail/1800.

[21] R. Shailam, A. Botwin, M. Stout, and M. S. Gee, "Real-Time Electronic Dashboard Technology and Its Use to Improve Pediatric Radiology Workflow," Current Problems in Diagnostic Radiology. 2017.

[22] J. M. Ferranti, M. K. Langman, D. Tanaka, J. McCall, and A. Ahmad, "Bridging the gap: 
Leveraging business intelligence tools in support of patient safety and financial effectiveness," $J$. Am. Med. Informatics Assoc., vol. 17, no. 2, pp. 136-143, 2010.

[23] J. Machado, E. Silva, and A. Abelha, "Business Intelligence Platform for Nosocomial Infection Incidence," vol. 10, no. March, 2017.

[24] J. P. Almeida, "A disruptive Big data approach to leverage the efficiency in management and clinical decision support in a Hospital," Porto Biomed. J., vol. 1, no. 1, pp. 40-42, 2016.

[25] N. Mustafee, J. H. Powell, S. Martin, A. Fordyce, and A. Harper, "Investigating the Use of Real-time Data in Nudging Patients' Emergency Department (ED) Attendance Behaviour," in Proceedings of the Symposium on Modeling and Simulation of Complexity in Intelligent, Adaptive and Autonomous Systems, 2017, p. 6:1--6:9.

[26] J. DeGaspari, "The 2013 Healthcare Informatics Innovator Awards: First Place Winner: NorthShore University HealthSystem," Heal. Mag., 2013.

[27] P. Subramanian, S. Palaniappan, M. Vedamanikam, N. Ujwal Bharat, and S. Sinnasamy, "EXPLORING THE EFFECTIVENESS OF DATA MINING TECHNIQUES FOR LUNG CANCER PREDICTION," 2016.

[28] D. Stålhammar, "Sahlgrenska University Hospital," Qlik, 2008. [Online]. Available: https://www.qlik.com/us/solutions/customers/cust omer-stories/sahlgrenska-university-hospital.

[29] O. Ali, P. Crvenkovski, and H. Johnson, "Using a business intelligence data analytics solution in healthcare," in 2016 IEEE 7th Annual Information Technology, Electronics and Mobile Communication Conference (IEMCON), 2016.

[30] K. Tsoi, F. Chan, and H. Hirai, "Data Visualization on Global Trends on Cancer Incidence An Application of IBM Watson Analytics," 50Th Hawaii Int. Conf. Syst. Sci., pp. 3283-3288, 2017.

[31] P. Loreto, F. Fonseca, A. Morais, H. Peixoto, A. Abelha, and J. Machado, "Improving Maternity Care with Business Intelligence," 2017 5th Int. Conf. Futur. Internet Things Cloud Work., pp. 170-177, 2017.

[32] L. K. Wickramasinghe, P. Schattner, K. Jones, and L. P. Am, "Chronic Disease Management : a Business Intelligence Perspective," in Proceedings of the Fifth Australasian Workshop on Health Informatics and Knowledge Managemen (HIKM 2011), Perth, Australia Chronic, 2011, no. Hikm, pp. 55-62.

[33] R. A. Simms, H. Ping, A. Yelland, A. J. Beringer, R. Fox, and T. J. Draycott, "Development of maternity dashboards across a UK health region; Current practice, continuing problems," Eur. J. Obstet. Gynecol. Reprod. Biol., 2013.

[34] C. Silva, J. Pereira, L. Costa, H. Peixoto, J. Machado, and A. Abelha, "Business Intelligence for Cardiovascular Disease Assessment," 2017 5th Int. Conf. Futur. Internet Things Cloud Work., pp. 186-193, 2017.

[35] T. A. Carte and A. B. Schwarzkopf, "Advanced Business Intelligence at Cardinal Health ADVANCED BUSINESS INTELLIGENCE AT CARDINAL," no. October, 2015.

[36] A. Ahmad, I. Muraina, R. Abd, and M. Syazwan, "Better Healthcare: Exploring Business Intelligence for Healthier Malaysian Rural Dwellers," no. June, pp. 25-27, 2013.

[37] Porter, "What is value in health care," $N$ Engl $J$ Med, vol. 363:26, no. 1, pp. 1-3, 2010.

[38] J. Hurh, Y. H. Ko, and S. S. Lee, "Value-based healthcare: Prerequisites and suggestions for fullfledged implementation in the Republic of Korea," J. Korean Med. Assoc., 2017.

[39] NEJM CATALYST, "What Is Value-Based Healthcare?," N. Engl. J. Med., 2017.

[40] G. E. Calabrò et al., "Avoidable blindness and value based healthcare: More value with a population approach," Epidemiology Biostatistics and Public Health. 2017.

[41] P. B. van der Nat et al., "Insights on value-based healthcare implementation from Dutch heart care," International Journal of Healthcare Management, pp. 1-4, 2017.

[42] K. Nilsson, F. Bååthe, A. Erichsen Andersson, and M. Sandoff, "Value-based healthcare as a trigger for improvement initiatives," Leadersh. Heal. Serv., 2017.

[43] M. E. Porter and T. H. Lee, "The strategy that will fix health care," Harv. Bus. Rev., 2013.

[44] Agency for Healthcare Research \& Quality, "Care Coordination," 2017. [Online]. Available: https://www.ahrq.gov/professionals/preventionchronic-care/improve/coordination/index.html.

[45] K. Nilsson, F. Bååthe, A. E. Andersson, E. Wikström, and M. Sandoff, "Experiences from implementing value-based healthcare at a Swedish University Hospital - an longitudinal interview study," BMC Health Serv. Res., 2017.

[46] R. Y. Tan and G. S. Tan, "Value-Based Healthcare in Residency Training: a Perspective from Singapore," Med. Sci. Educ., 2017.

[47] P. Nordin, A.-A. Kork, and I. Koskela, "Leadership in Health Services Value-based healthcare measurement as a context for organizational learning: Adding a strategic edge to assess health outcome?," Heal. Serv., vol. 30, no. 2, pp. 159-170, 2017.

[48] N. Hansen and E. Vincent, Measured Outcomes A Future View of Value Based Healthcare. Health Catalyst, 2015.

[49] T. W. Feeley, H. W. Albright, R. Walters, and T. W. Burke, "A method for defining value in healthcare using cancer care as a model.," $J$. Healthc. Manag., vol. 55, no. 6, pp. 399-412, 2010.

[50] I. Putera, "Redefining Health: Implication for Value-Based Healthcare Reform," Cureus, 2017. 